\title{
Compositional and micromorphological features of hypoplastic enamel in children's permanent teeth
}

\author{
Natalya Ozhgikhina ${ }^{1, *}$, Daria Kiseleva ${ }^{2}$,Evgeny Shagalov ${ }^{2}$, Evgenia Bimbas ${ }^{1}$, and Natalya \\ Myagkova $^{1}$ \\ ${ }^{1}$ Ural State Medical University, 620028, Repin Str., 3, Ekaterinburg, Russian Federation \\ ${ }^{2}$ A.N. Zavaritsky Institute of Geology and Geochemistry UB RAS, 620016, Ekaterinburg, Russian \\ Federation
}

\begin{abstract}
Enamel hypoplasia is the most common disease of hard tooth tissues of non-carious origin emerging before their eruption. It develops as a result of a delayed and perverse function of ameloblasts leading to the violation of the processes of formation and mineralization of tooth protein structures. The clinical manifestations of enamel hypoplasia are spots, defects in the form of pits, cup-shaped depressions, grooves on various surfaces of child's teeth. The work is devoted to a comparative investigation of microstructural and compositional features of intact and hypoplastic enamel in children's permanent teeth using analytical scanning electron microscopy with energy-dispersive X-ray spectroscopy. The hypoplastic enamel is enriched in organic substance and has an irregular structure without keyhole-shaped prismatic structure. Mineral deposition is indicated for hypoplastic enamel including hydroxyapatite with globular structure and calcite and halite, which might have been caused by the violation of extracellular local environment probably due to the enamel hypoplasia development.
\end{abstract}

\section{Introduction}

Phosphate biominerals of human tooth enamel and dentin consist mainly of $\mathrm{Ca}_{10}\left(\mathrm{PO}_{4}\right)_{6}(\mathrm{OH})_{10}$ hydroxyapatite mineral and are characterized by complex variable microstructure, morphology and chemical composition [1-3]. Enamel and dentin properties depend on biogeochemical conditions of residence area, ecological and professional factors, age, concomitant diseases, etc. Tooth enamel and dentin structure and texture peculiarities (such as specific surface area and volume, average size and the form of particles and pores, etc.) determine its physical-chemical and physiological properties like strength, penetrability, efficiency of exchange processes and others [1]. The morphology, chemical composition and structure of enamel are the main factors determining tooth resistance to carious and non-carious lesions.

\footnotetext{
*Corresponding author: agat325@mail.ru
} 
Enamel hypoplasia is the most common disease of hard tooth tissues of non-carious origin, which forms before they erupt [4,5]. An epidemiological dental examination conducted in 2009 has shown that the average prevalence of dental hypoplasia in 12-yearold children is $27 \%$ and in 15 -year-olds - $28 \%$ [6]. According to foreign authors, the prevalence of enamel hypoplasia is from 5 to $40 \%$ [7,8].

Enamel hypoplasia is the result of a delayed and perverse function of ameloblasts, a violation of the processes of formation and mineralization of tooth protein structures. The disease is characterized by a disturbance of the enamel structure of all teeth or a group of teeth forming at the same time. This pathology arises as a result of the development of pathological processes in the fetus and a child body of the first years of life such as hyperthermia, hypoxia, hypocalcemia, intoxication, and the effect of antibiotics.

The clinical manifestations of enamel hypoplasia are spots, defects in the form of pits, cup-shaped depressions, grooves on various surfaces of child's teeth. N.V. Ozhgikhina and L.P. Kiselnikova [5,9] have reported a high prevalence of caries in the permanent teeth of children with enamel hypoplasia (87.09\%). The intensity of caries of permanent teeth in 12 year-old children with a spotted form of hypoplasia and with hypoplasia in the form of a defect is 2.5 times higher than in children with normally formed enamel [9]. The carious process that develops against the background of hypoplastic enamel is proceeding actively, with several carious cavities appear on one tooth. Thus, when studying the characteristics of the occurrence and course of caries in children with enamel hypoplasia, early occurrence of carious cavities with primary localization in the area of hypoplastic enamel, a high prevalence and acute course of the carious process in permanent teeth were found [10-12].

Scientific reports concerning the studies of microstructure, composition and mechanical properties of hypoplastic teeth by analytical spectroscopic and microscopic methods with high spatial resolution are rather scarce. Using electron microprobe and hyperspectral Raman imaging, Wang et al. [13] have identified a correlation of spectral peak position and linewidth as a measure of crystal lattice disorder across tubules, dentin, dentin-enamel junction, and enamel for intact and hypoplastic teeth.

The mechanical properties (Vickers microhardness test) of deciduous hypoplastic enamel (pitted and smooth form) caused by AI (Amelogenesis Imperfecta) have been investigated by Pavlič et al. [14]. They found that the values of microhardness in pitted hypoplastic AI samples were, on average, lower as compared to the control enamel and dropped markedly towards the dentine-enamel junction. The smooth hypoplastic enamel was not only extremely thin but also much softer than control (intact) enamel [14]. The microstructure of AI enamel was evaluated using scanning electron microscopy (SEM).

The investigation of the nanoscratch resistance of hypoplastic amelogenesis imperfecta enamel and dentine [15] using atomic force microscopy (AFM), energy-dispersive X-ray (EDS) spectroscopy and a nanoscratch tester has indicated that hypoplastic teeth have different microstructures as compared to normal teeth; hypoplastic amelogenesis imperfecta demonstrated a higher amount of organic substance.

The aim of the work is to perform a comparative investigation of microstructural and compositional features of intact and hypoplastic enamel in children's permanent teeth using analytical scanning electron microscopy with energy-dispersive X-ray spectroscopy (SEMEDS). 


\section{Materials and Methods}

\subsection{Sample preparation}

Three permanent teeth with enamel hypoplasia (molar, premolar and incisor) and one intact incisor were extracted from children patients (aged 9-10) of the dental clinic of Ural State Medical University (Ekaterinburg, Russia) for dental health reasons with free written patient consent. Teeth with hypoplasia had lesions of different severity (white spots and yellow or brown enamel) (Fig. 1).

The extracted teeth were thoroughly cleaned with deionized water and dried then stored in sealed plastic bags. Dry teeth were washed in distilled water for $10 \mathrm{~min}$, then dried, and cleaned using ethanol.
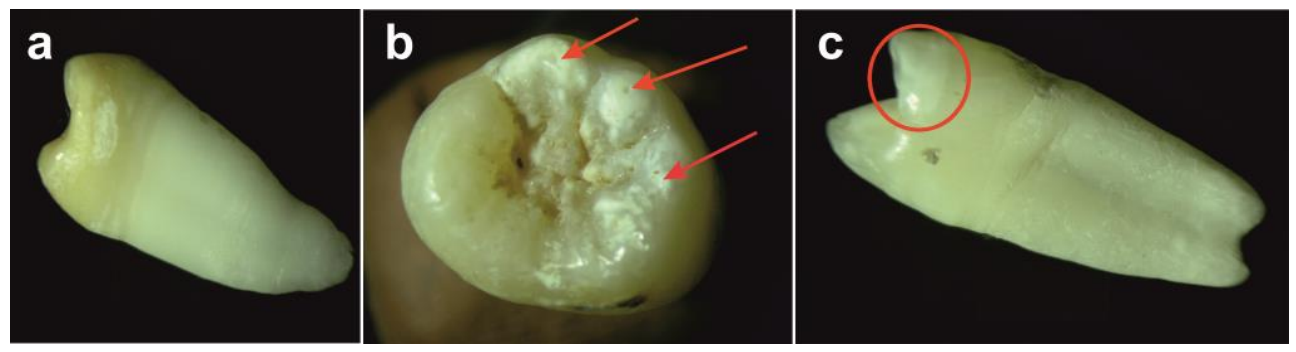

Fig. 1. Hypoplastic teeth under study: hypoplasia across the entire tooth crown with caries white spot, premolar (a); spot hypoplasia on the buccal cusp, molar (b); spot hypoplasia on the buccal cusp with caries, premolar. Red arrows and circle mark the hypoplasia localization.

\subsection{Scanning electron microscopy - energy-dispersive X-ray spectroscopy (SEM-EDS)}

SEM imaging and EDS analysis of the tooth samples is performed at the A.N. Zavaritsky Institute of Geology and Geochemistry UB RAS, Ekaterinburg, using a JEOL JSM6390LV scanning electron microscope with an Oxford Instruments Inca X-Max energy dispersive spectrometer at an accelerating voltage of $20 \mathrm{kV}$. The samples were carbon sputtered prior to analysis.

\section{Results and Discussion}

On the microscale level, SEM images from hypoplastic enamel show a cracking irregular structure of superficial enamel layers with no enamel prisms (Fig. 2e and f). In contrast, intact enamel reveals typical keyhole-shaped enamel prisms (Fig. 2b) even in hypoplastic teeth (Fig. 2d and 3a). According to EDS data, intact enamel is composed of hydroxyapatite (EDS spectral insert in Fig. 2b). $\mathrm{Ca}$ and $\mathrm{P}$ are the major elements with the traces of $\mathrm{Na}, \mathrm{Mg}$ and $\mathrm{Sr}$ and $\mathrm{Cl}$ and $\mathrm{S}$ anions (or either sulphur can be a part of organic constituent like proteins).

Dark colored areas in SEM images of hypoplastic enamel correspond to the regions with high organic content which is in agreement with the conclusion of Pavlič et al. [15] that hypoplastic amelogenesis imperfecta enamel demonstrates a higher amount of organic substance.

A boundary between dark and light spots on enamel surface (Fig. 2e and f) is clearly identified, which discriminates the mineralized region from organic-enriched area. This area is characterized by the presence of newly-formed minerals such as calcite and halite 
(Fig. $2 \mathrm{~g}$ and h). A boundary between organic-enriched hypoplastic and intact enamel (Fig. $3 a$ and $b$ ) is characterized by the development of cracks filled by organic-enriched substance.
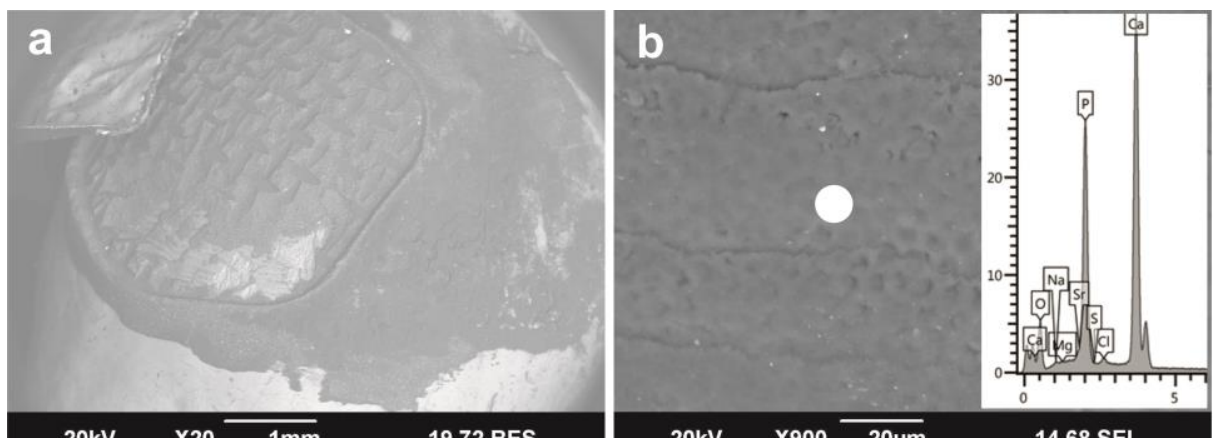

$20 \mathrm{kV} \quad \mathrm{X} 20 \overline{1 \mathrm{~mm}} \quad 1972 \mathrm{BES}$
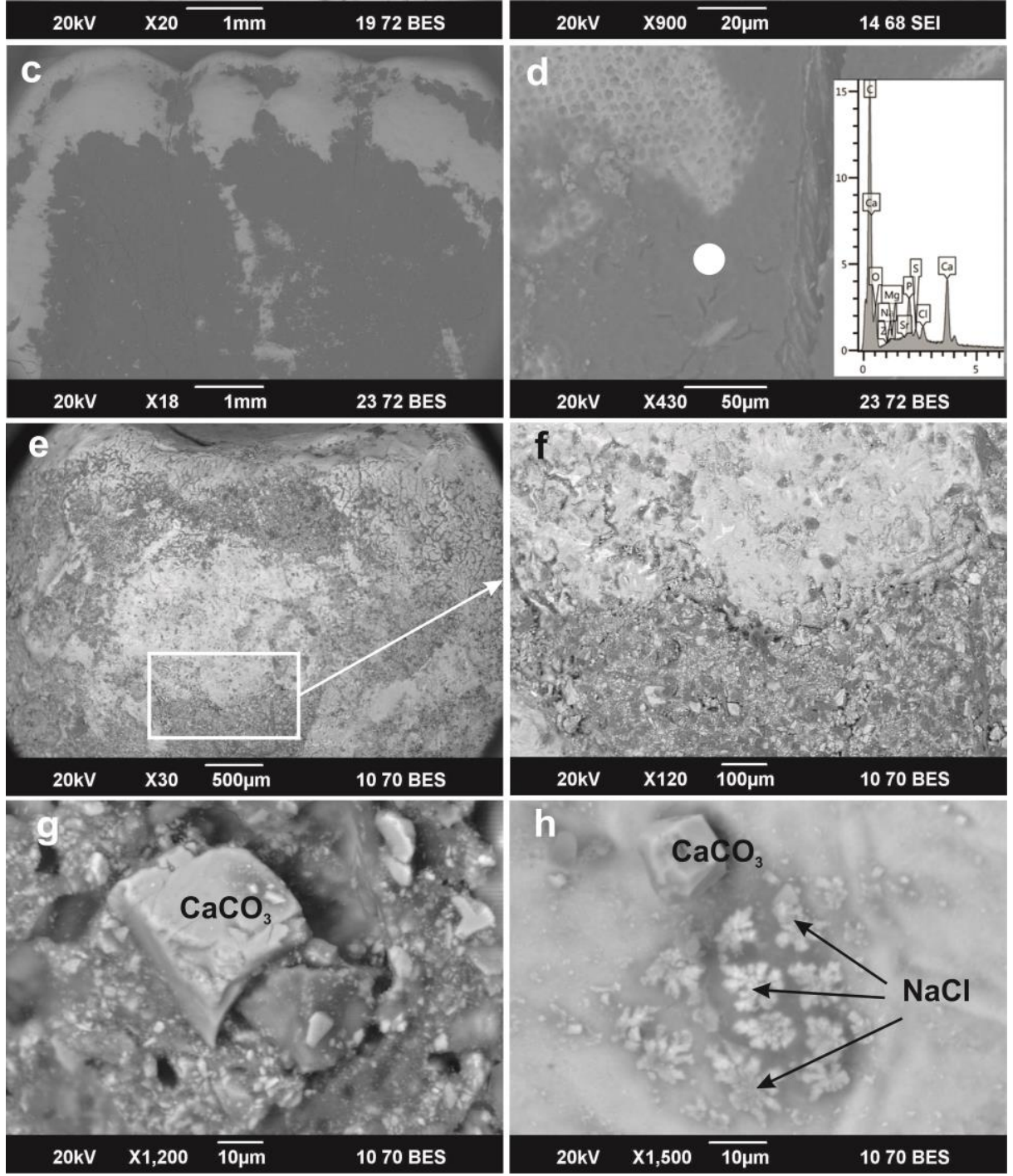
Fig. 2. SEM images of intact (a-b) and hypoplastic (c-h) teeth. Dark color corresponds to the regions with high organic content (see EDS spectrum) (d). Regular prismatic structure of enamel is clearly visible (b,d) with EDS spectra corresponding to hydroxyapatite mineral. A boundary between dark and light spots on enamel surface $(\mathrm{e}, \mathrm{f})$ is identified discriminating the mineralized region from organic-enriched area, which is characterized by newly-formed (calcite, halite) mineral deposition $(\mathrm{g}, \mathrm{h})$. Filled white circles are EDS analytical points.
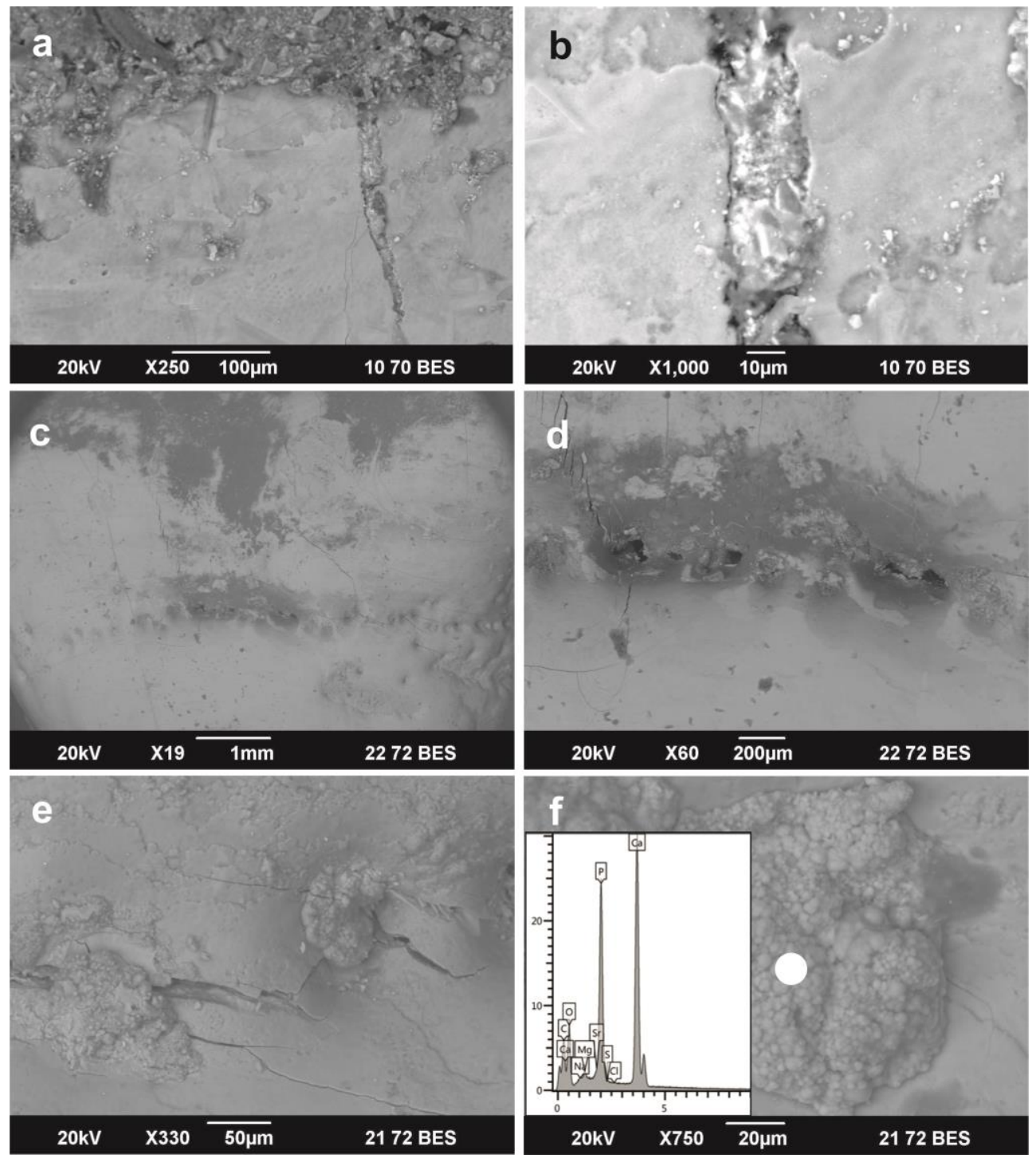

Fig. 3. SEM images of hypoplastic teeth. Cracks filled by organic-enriched substance $(a, b)$ on the boundary between hypoplastic and intact enamel (a). A pitted form of hypoplasia (c,d) with globular hydroxyapatite aggregations (e,f). Filled white circle is EDS analytical point.

Fig. $3 \mathrm{c}$ and $\mathrm{d}$ demonstrates a pitted form of hypoplasia with globular mineral aggregations deposited in the pit depressions, which is composed of hydroxyapatite (EDS spectral insert in Fig. 3f).

$\mathrm{CaCO}_{3}$ calcite has a rhombohedral habit similar to observed by Li et al. [16] during the experimental growth of calcite in confinement simulating biomineralization processes 
under the controlled flow of supersaturated $\mathrm{CaCl}_{2}+\mathrm{Na}_{2} \mathrm{CO}_{3}$ solution. The observed calcite morphology and its polymorph appears largely to be a consequence of the growth mechanism as determined by the solution supersaturation, which in turn, is dictated by the local chemical environment, its anionic and cationic composition and $\mathrm{pH}$ [17]. $\mathrm{NaCl}$ halite crystals have dendritic habit which appears when crystals grow by evaporation from aqueous solution with the high values of the supersaturation [18].

Since crystal growth (both biogenic hydroxyapatite and newly-formed salts) is modulated by changes in the $\mathrm{pH}$ of the enamel microenvironment [19], it is one of the factors critical for proper enamel biomineralization. $\mathrm{pH}$ values are maintained in nearneutral conditions $(\sim 7.2)$ during ameloblast secretion, whereas the extracellular $\mathrm{pH}$ shows considerable variation during maturation, shifting from acidic to near-neutral values, then rising to higher $\mathrm{pH}$ levels in more mature enamel [19]. Thus, $\mathrm{pH}$ affects the stoichiometry of the crystals, as the ratios of mineral content differ between acidic and alkaline regimes [19].

Since the genetic base for amelogenesis imperfecta is generally associated with mutations to enamel matrix specific genes, the mutations of genes involved in $\mathrm{pH}$ regulation (involving carbonic anhydrases, which generate local bicarbonate, chloride, and bicarbonate cotransporters permitting the passage of bicarbonates from external sources) may result in severely affected enamel structure [19].

The deposition of newly-formed salts and globular hydroxyapatite on enamel surface might have occurred due to the violation of $\mathrm{pH}$ homeostasis, probably genetically driven, which have led to the formation of supersaturated solution containing $\mathrm{Ca}, \mathrm{Cl}$ and $\mathrm{Na}$ ions and $\mathrm{HCO}_{3}{ }^{-}$bicarbonate-ion ( $\mathrm{pH}$ buffer in enamel) transformation into $\mathrm{CO}_{3}{ }^{2-}$ carbonate ion under alkaline conditions.

\section{Conclusion}

Our study has demonstrated significant differences between intact and hypoplastic enamel, which are manifested through the micromorphological features of enamel surface. The violation of normal biomineralization process is reflected in the irregular structure of hypoplastic enamel enriched in organic substance, where typical keyhole-shaped enamel prismatic structure is not observed. Mineral formation is indicated for hypoplastic enamel including the deposition of hydroxyapatite with globular structure and calcite and halite, which might have occurred due to the violation of extracellular local environment $(\mathrm{pH}$, anionic and cationic composition, etc.) apparently caused by the enamel hypoplasia development.

The work was carried out at the UB RAS "Geoanalytic" Center for Collective Use within IGG UB RAS state assignment № AAAA-A18-118053090045-8.

\section{References}

1. W. J. Landis, Bone, 16, 533-544 (1995)

2. Y. Pan, M. Fleet, Rev. Mineral. Geochem., 48, 13-50 (2002)

3. J. C. Elliott, Rev. Mineral. Geochem., 48, 427-453 (2002)

4. R. R. Welbury, M. S. Duggal, M. T. Hosey, Paediatric Dentistry (GEOTAR, Moscow, 2013)

5. V. K. Leontiev, L. P. Kiselnikova, Pediatric therapeutic dentistry (GEOTAR-Media, Moscow, 2017)

6. E. M. Kuzmina, Dental disease incidence in the Russian population (MGMSU, Moscow, 2009)

7. V. E. Beentjes, K. L. Weerheijm, H. J. Groen, Eur. J. Paediatr. Dent., 1, 9-13 (2002) 
8. S.G. Reed, C.S. Miller, C.L. Wagner, B.W. Hollis, A.B. Lawson, Caries Res., 54(1), 55-67 (2020)

9. N.V. Ozhgikhina, T.V. Zakirov, L.P. Kiselnikova, Pediatric dentistry and dental profilaxis. 4, 26-30 (2019)

10. R. J. Vargo, R. Reddy, W. B. Da Costa, L.R.F. Mugayar, J. Paediatr. Dent., 30(2), 216$224(2020)$

11. N.-Y. Shin, H. Yamazaki, E. Beniash, X. Yang, S. S. Margolis, J. Biol. Chem. 295(7), 1943-1959 (2020)

12. F. Jeremias, J.F. de Souza, C.M. da Costa Silva, R. de Cássia Loiola Cordeiro, Acta Odontol. Scandinavica, 71(3-4), 870-876 (2013)

13. P. Wang, E.J.D. Anderson, E.A. Muller, F. Gao, Y. Zhong, M.B. Raschke, J. Raman, Spectrosc., 49(9), 1559-1567 (2018)

14. A. Pavlič, P. Škraba, L. Kosec, M. Petelin, S. Alaluusua, CEJ Med. 2, 511-27 (2007)

15. P. Qing, Y. Li, S. Gao, M. Qiao, L. Qian, H. Yu, Adv. Mech. Eng., 7(7), 1-8 (2015)

16. L. Li, F. Kohler, A. Røyne, D.K. Dysthe, Crystals., 7, 316 (2017)

17. E. Asenath-Smith, H. Li, E. C. Keene, Z. Wei Seh, L. A. Estroff, Adv. Funct. Mater. 22(14), 2891-2914 (2012)

18. D. Aquilano, F. Otálora, L. Pastero, J. M. García-Ruiz, Prog. Cryst. Growth. Ch., 62(2), 227-251 (2016)

19. R.S. Lacruz, A. Nanci, I. Kurtz, J.T. Wright, M.L. Paine, Calcif. Tissue. Int., 86(2), 91$103(2010)$ 